\title{
Women, ethnic minorities and newsworthiness: Journalists' perceptions
}

\begin{abstract}
This study seeks to determine the extent to which the Flemish press gives voice to gender and ethnic diversity. Sixteen in-depth interviews with print journalists outlined five key arguments about diversity in the newsroom. Two of these view the portrayal of diversity as conceptually process or inconsistent with a notion of universal equality. The third argument defines diverse representation as an active search process that is part and parcel of a journalist's mission. Two additional arguments blame the lack of diversity in news reporting on practical obstacles - professional practices that make it difficult to aim for a diverse source selection, or the less prominent role of women and ethnic minorities in society which boils down to a less diverse set of news sources.
\end{abstract}

\section{Keywords}


Ethnicity; gender; interview study; journalism culture; news diversity; news sources

\section{Introduction}

The purpose of this study is to examine the extent to which Dutch-language Belgian ${ }^{(1)}$ print journalists incorporate gender and ethnic diversity in their reporting. From a critical normative perspective the news media are expected to give a representative picture of all people within society (Malik, 2014; McQuail, 2010). Within a Western European policy context this has been the prevailing interpretation of the way they need to fulfill their democratic function since the 1970s (Horsti et al., 2014). The need for them to mirror differences within society - 'diversity as reflection' (McQuail, 1992) - is inextricably linked to multiculturalism (Voakes et al., 1996), especially in Europe where immigration has gradually turned most countries into multicultural and ethnically diverse societies. Thus since the 2000 s the representative function of the media has been seen as a tool to promote identity diversity with a view to enhancing cohesion within a multicultural society (O'Loughlin, 2006). To fully stimulate social cohesion, news media should act as 'general representatives' - that is to say they should account 
for the realities of all demographic groups in society, be they in the majority or minority (Gans, 2011).

Basically, this representation function entails giving all demographic groups their fair share of news space, which in practice amounts to consulting them as sources. Such visibility in the news affords these groups a measure of power, and thus improved social status (Avraham and First, 2010). Expressing one's views in the media is a minimum requirement to exert influence, which can lead to reshaping public opinion or actuating policy (Duncun and Reid, 2013). But the systematic underrepresentation of specific demographic groups fosters the notion that such groups have a lower social status in society - that is, a feeling that they do not really matter. Silverstone (2008) calls this phenomenon 'symbolic annihilation' or 'social exclusion'.

This study focuses on two demographic groups: women and ethnic minorities. Both groups are consistently underrepresented in the news media. Since the 1960s the representation of women in the media is high on the political and research agenda (Soderlund, 2013). Despite the increasingly prominent roles of women worldwide, gender equality seems as unattainable a goal as ever (Ross et al., in press). In 2015 a study of the Global Media Monitoring Project (WACC, 2015) identified a huge gender 
imbalance: $26 \%$ female versus $74 \%$ male news subjects in traditional news media. In the last 20 years this imbalance was only reduced by $7 \%$. In addition, when women do appear in news stories they are often represented in a stereotyped manner, with the journalist needlessly insisting on their femaleness, for instance (e.g. Ross et al., in press; Ross and Carter, 2011). Hence, it remains important to strive for a better representation of women in the news. A higher proportion of female subjects in all types of news stories has a clearly positive impact both in terms of actual gender equality nationwide and attitudes about gender roles among the general population (Djerf-Pierre, 2011).

Europe has become an ethnically diverse society, and Flanders is no different. In such a multicultural context ethnic minorities need access to the media to gain social status and better integrate into society (Avraham and First, 2010). Unfortunately, the literature shows they are hardly represented, and when they actually are, they are depicted in a stereotyped fashion (e.g. Gemi et al., 2013; Ter Wal et al., 2005). In the long run this misrepresentation/underrepresentation of ethnic minorities colours the perceptions of audiences and journalists alike, encouraging them to associate such societal problems as criminality with ethnicity (Dixon and Williams, 2015). 
It is clear that women and ethnic minorities are underrepresented, but which level of representation might we think is 'good enough'? In the strict sense representation can be interpreted as a reflection of societal reality, which Napoli (1999) defined as demographic diversity: the extent to which the various demographic groups are given a voice in direct proportion to their prevalence in society. In this study 'prevalence in society' is used as a criterion in assessing the representation of minority groups. However, this should not be viewed as an end in itself. Theoretically the full meaning of representative diversity is open diversity: giving equal access in the news content to all perspectives of all demographic groups in society, regardless of their actual weight (Van Cuilenburg, 2016).

Despite systematic research into the underrepresentation and stereotypical imaging of women and ethnic minorities, we currently know very little of the hegemonic and homogenizing mechanisms at play within the news production process. In the next section, we look at the representation of diversity as a component of the professional standards of journalism.

\section{Portraying diversity a hallmark of professionalism}


Objectivity and journalistic culture as a framework for understanding diversity

In Western democracies objectivity stands among the main professional standards for journalists (e.g. Skovsgaard et al., 2013, Robinson and Culver, in press). In the traditional liberal sense, it means mirroring society through collecting and disseminating all the information citizens need to form a good idea of societal problems (e.g. Napoli, 1999; Raeijmaekers and Maeseele, 2015). Skovsgaard et al. (2013) identify two journalistic approaches to act as disseminator of representative information: a passive (mirror) or an active approach (watchdog). The passive approach can be seen as the old interpretation of the duty of objectivity as mimetic representation of reality. Here the news media play a part in preserving and reproducing entrenched power relationships (Robinson and Culver, in press). In other words a group that plays a less important role in society is rarely portrayed in the news, and as a result is unable to improve its status, which leads to a lack of cohesion in society. To enhance social cohesion the news media should also represent non-powerful groups. To fulfill this goal an active interpretation of objectivity is needed - one that journalists are willing to actively work on so as to represent currently 
disenfranchised demographic groups (Deuze, 2005). This active approach to objectivity as a spectrum of perspectives is becoming increasingly prominent in the literature (e.g. Dixon and Williams, 2015; Robinson and Culver, in press; Ward, 2010). However, a prerequisite to ending current misrepresentations of underprivileged groups such as immigrants is that journalists choose to play their watchdog role: controlling and correcting for power not only with respect to government but to society as a whole (Broersma and Peters, 2017; Dixon and Williams, 2015).

Of course the so-called mirror and watchdog roles are theoretical, ideal types; the way journalists put them into practice is quite a different matter (Wiik, 2014). In other words it is useful to look at journalism from a functional perspective in a daily work context (Broersma and Peters, 2017; Deuze, 2005). Therefore this study looks at the concrete ways in which journalists practice objectivity with respect to women and ethnic minorities. The framework in which such interpretations of objectivity are given meaning is journalism culture - that is the sum of ideas, principles and practices on which journalists base their belief in the usefulness of their work for society (Hanitzsch, 2007: 369). Hanitzsch (2007) premised a typology for journalism culture. This typology is adapted to our study with its three categories (a. social responsibilities; b. truth evaluation, and c. 
ethical standards) and five dimensions (within a. involvement and power position; within b. objectivism; within c. relativism and idealism) in which we linked the ideal types of each dimension with either an active or a passive journalistic approach. This leads us to the following research question:

RQ1: How do the journalistic arguments in favour or disfavour of a diverse source selection relate to the active versus passive approaches of the ideal types of journalism culture?

This typology will be implemented in the context of a diverse range of news sources. First, for each dimension the active ideal type will be explained, followed by its passive counterpart. The social responsibilities category has two dimensions: 'involvement', and 'power position'. Within the involvement dimension a journalist can assume her or his 'commitment' to society by looking for diverse news sources to advocate social change (Hanitzsch et al., 2011). The opposite interpretation is 'disengagement' or assuming no responsibility to society, and consequently failing to see how a diverse news source selection might be at all beneficial. The second dimension is the position journalists take with respect to power relationships, with 'change' as the active ideal type and 'conservation' as the passive one. Journalists with a sense of the greater good see themselves as 
agents of social change and they strive to balance such power relationships in society. As a result they will attempt to enhance the social status of women and ethnic minorities by representing them more often. On the contrary, journalists who define themselves as government figureheads are loyal to whoever is in power and seek to maintain the current power imbalance.

A second component of journalism culture deals with the evaluation of truth. A journalist's interpretation of objectivity depends on which 'truth' she or he believes in, with 'reconstruction' and 'reproduction' being the ideal types. The first option is to reconstruct such truth by identifying all of its aspects - the various viewpoints on an issue. Here representing 'truth' is an active search process, consistent with Socrates's dialectical, truth-seeking method (synthesis) which seeks to balance conflicting perspectives (thesis and antithesis). All aspects of such truth - both minority and mainstream views - are afforded some news space in order to provide a balanced picture. The theoretical, ideal representation of these viewpoints (open diversity standard) gives them all equal coverage, no matter their actual weight in society. In contrast, a journalist who views truth as a reflection or mimetic reproduction of reality assumes she or he only needs to report on the dominant aspects. Here the news content merely reflects 
the majority view, which serves to uphold the social consensus (Raeijmaeckers and Maeseele, 2015).

The third and last category, ethical standards, is about the ethical choices journalists have to make. Within his typology of journalism culture, Hanitzch distinguishes two dimensions: 'relativism' and 'idealism'. The relativism dimension stands for the extent to which journalists believe in universal ethical rules (i.e. universality versus contextuality). If journalists believe that women and ethnic minorities should enjoy equal representation with men and the ethnic majority, they assume a responsibility to society. However, if they see such a rule as contextual, they do not even have to consider any ethical implications. The idealism dimension addresses the ethical standpoint with a vision which takes heed of nothing beyond results (outcome-oriented), while another approach highlights the way in which a result is obtained (means-oriented). The relativism and idealism dimensions are interconnected, giving rise to four possible combinations. First, 'absolutism' as the idealistic form of non-relativism (universal and meansoriented): only by following universal ethical rules can journalists make news stories. In that case they consider the representation of women and ethnic minorities in news reporting as the condition to achieve equality in society. Second, 'exceptionalism' suggests that universal rules are necessary 
but not applicable to every situation. This is an absolute realistic view (i.e. universal and outcome-oriented) in which journalists heed ethical rules at their discretion. In that case representation is important as a rule, but equal representation in news is not the (only) way to attain equality. Third, 'situationism' implies a relativistic idealistic view (i.e. contextual and meansoriented), which evaluates every situation separately and considers moral values in order to bring the best possible result. In that case, the representation of women and ethnic minorities can be seen as a way to achieve equality in society, although the rule is not always applicable. Four, 'subjectivism' is the relativistic version of the non-idealistic view (i.e. contextual and outcome-oriented): journalists create their own realities on the basis of their personal moral values. As such, representation in news reporting is not rated as a way to achieve equality in society. What is more, even equality in society is not an issue as seen from the journalist's perspective.

There have been calls to impose equal treatment of all individuals, irrespective of their ethnic descent or gender, as part of a universal ethical standard in journalism (Herrscher, 2002: 281) - a standard that would require of journalists that they devote as much space to women and ethnic minorities as they do to men and the mainstream majority. Adding diversity 
portrayal to journalistic standards could increase openness among journalists and consequently the degree of diversity in the news stories they produce. In a corporate context acceptance of diversity as an ethical standard is known to lead to greater openness among employees, both in the workplace and in daily life (Valentine and Fleischman, 2002). But accepting diverse representation as an ethical standard is one thing, actually living up to it is quite another. To what extent do journalists apply such a standard in their news reporting? Firstly, this depends on whether they view it as realistic, since if they do not, it will remain dead letter (Herrscher, 2002). For instance in 2003 the Flemish PSB (VRT) launched a Charter of Diversity in the hope of increasing diversity in its content. Notwithstanding this policy change the channel's newscasts did not end up presenting a more balanced picture of ethnic minorities than those of its commercial competitors (Van den Bulck and Broos, 2011). Secondly, a more balanced representation of diversity will depend on how journalists interpret and internalise ethical standards. Subscribing to the absolutism norm is necessary to place this issue high on the agenda, while subjectivism rejects this idea completely.

Social responsibility and journalism culture in Flanders 
Journalism culture is used as a conceptual framework to understand whether or not journalists are willing to take diversity into account while selecting news sources. Although these arguments are made on an individual level, the interpretation of professional standards is based on a shared cultural background (Hanitizsch et al., 2011). Consequently, this study provides insight in the journalism culture in Flanders and other regions with a similar culture. According to the comparison of media systems by Hallin and Mancini (2004), Flanders belongs to the Democratic Corporatist Model or North/Central European Model, which implies that the results can be extrapolated to the countries within this model. As social responsibility is one of the highly valued standards within the model, one might expect diverse representation to be high on the agenda of the journalists interviewed. But in a comparative study of journalism cultures in 18 countries (Hanitzsch et al., 2011), in addition to the United States, three countries (Austria, Germany and Switzerland) that belong to the Democratic Corporatist Model scored the lowest on willingness to advocate for social change, an important component of diverse representation. Another study (Wiik, 2014) indicated that over the last decades Swedish journalists had been moving from the Democratic Corporatist Model towards the Liberal 
Model, with objectivity as the overall professional standard. Such homogenisation can be explained by the increasing commercialisation of the news industry. Reaching a large and heterogeneous audience has become crucial, 'objectivity' being the means to achieving that objective (Wiik, 2014). This ends up in the following research question:

RQ2: Do Flemish journalists evaluate objectivity in the specific case of representing women and ethnic minorities in an active (i.e., highlighting the social responsibility factor of the Democratic Corporatist Model) rather than a passive way (following the Liberal Model)?

An important argument is the specificity of the representation of ethnic minorities. In the current multicultural context this is a key social issue (Deuze, 2005), albeit extremely delicate. This sensitivity can have an influence on the extent to which journalists assume social responsibility. Especially since the September 11, 2001 terrorist attacks in the USA there seems to have been a dramatic shift in the interpretation of multiculturalism and integration in Western Europe, and Flanders is no exception (Bousetta and Jacobs, 2006). The previous multicultural stance has given way to an approach that tends to favour the integration or even assimilation of ethnic minorities into the dominant culture. In the 1980s there was a general 
consensus to present ethnic minorities in a favourable light, for instance by concealing the ethnic descent of criminals. But since the 1990s and the rise of far-right politics, any concern or action deemed 'multicultural' tends to be tarred with the 'political correctness' label (Jakubowicz, 2014). In the Netherlands, a country which also belongs to the Democratic Corporatist Model, a recent study (Müller and Frissen, 2014) showed that journalists now tend to shun political correctness in their representations of ethnic minorities, no longer shying away from reporting problems related to the latter.

\section{Method}

In an effort to gauge the place of gender and ethnic diversity on the journalistic agenda, in-depth interviews were conducted with journalists. This method is the most appropriate to gain insight into individual thoughts on

diverse representation as it gives interviewees an opportunity to explain themselves. Hence, it is possible to capture exhaustive and varied information about individual experiences, opinions and motives.

Sixteen interviews were conducted in the autumn of 2013 with journalists working for four Flemish newspapers: two of the most widely 
read tabloids (Het Nieuwsblad and Het Laatste Nieuws) and two of the most read quality papers (De Morgen and De Standaard). To compile the sample of interviewees, four selection criteria were applied. First, all journalists had to be working on domestic news as ethnic diversity is linked with geography. Second, to avoid the gender effect, two men and two women were selected per title. Third, the age of the journalists was used as an indicator of professional experience. The respondents were aged between 24 and 63, with an average of 38 . One journalist had more than 40 years' experience, one over 30 years, three over 20 years, five over 10 years and another six less than 10 . The last criterion was the journalists' ethnicity. One was from a non-EU background, which is representative for Flanders, where $4 \%$ of journalists were born outside Belgium and $5 \%$ have one parent who was born outside Belgium, the Netherlands and France (Raeymaeckers et al., 2013).

A semi-structured interview strategy was adopted to allow participants to talk freely and openly, while making sure they gave their opinion about the same elements. They were first asked how they understood diverse representation as part of their daily activities, and then to indicate the extent to which they agreed with general statements about diversity in the 
context of their work (e.g. "Journalists should give a voice to everyone in their news stories").

Further, the interviewees were asked to assess the facts, i.e. the proportion of women as well as ethnic minority members as news subjects in the Flemish press (authors). The results of the content analysis were consistent with the above-mentioned literature. While women make up $50.9 \%$ of the general population, only $16.3 \%$ of news subjects were female. The most balanced male/female ratio had to do with the well-being sections of the papers $(39.4 \%$ female). Similarly, with ethnic minorities making up $9 \%$ of the population, only $3.3 \%$ of news subjects in the Flemish press turned out to be members of an ethnic minority. Within this group, $41.3 \%$ was mentioned in the context of criminality.

Last, the interviews sought to shed light on the source selection procedures (e.g. "If you want to hear the opinion of the man in the street, how are you going to proceed?"). Based on at least five recent articles she or he had worked on, each journalist was asked to describe the way they selected their sources, following a so-called reconstruction interview approach (Reich, 2009).

Respondents were guaranteed anonymity. The interviews lasted between one and two hours and were recorded with the consent of each 
interviewee. All interviews were conducted by the first author, so the interviewer effect remained constant throughout. Finally, the interviews were transcribed.

Interview transcripts were coded based on a theoretical thematic analysis (Braun and Clarke, 2006) using the NVivo 10 software package. The analysis consisted of the following stages. First, the interviews were read in detail and open codes were attributed. In the next stage, selective coding was used to merge the identified codes into three main themes: definition of diversity, conceptual relevance of diversity, and practical obstacles to diverse representation. These codes and themes were then linked with journalistic roles based on the typology of journalism cultures. The various themes were compared and crosschecked, and their interrelationships examined.

In the following section the findings will be discussed and illustrated with quotations from the interviews. The selected quotations are those that best reflect the viewpoints with respect to the arguments raised about portrayal of diversity.

\section{Results}


The open-ended question on the definition of diversity showed that the journalists generally associated it with identity diversity, specifically the gender and ethnicity of the news source. While 13 out of the 16 journalists indicated the man-woman dilemma as a diversity issue, 12 out of 16 associated diversity with the ethnicity of the news source. However, there was no agreement on the question whether the portrayal of gender and ethnic diversity should be part of their mission. There were five arguments to be found in the way journalists interpret diversity in their daily work context (Table 1). Two arguments basically resist the idea of diverse representation, one owing to an 'incompatibility' with news making, the second because it allegedly departs from a principle of equality between people. A third line of reasoning endorses the notion of diverse representation, and two more focus on the practical obstacles to diverse representation - immutable news routines or lack of diversity in societal reality. In the following pages we shall analyse each argument based on the proposed interpretation of Hanitzsch's (2007) typology of journalism culture.

Table 1. Diverse representation: five lines of reasoning applied to the ideal types of journalistic culture. 


\begin{tabular}{|c|c|c|c|c|c|}
\hline & \multicolumn{3}{|c|}{ Conceptual relevance } & \multicolumn{2}{|c|}{ Practical obstacles } \\
\hline & $\begin{array}{c}\text { Diverse } \\
\text { representation } \\
\text { incompatible with } \\
\text { news making (1) }\end{array}$ & $\begin{array}{l}\text { Equality is a } \\
\text { reality (2) }\end{array}$ & $\begin{array}{c}\text { Diverse } \\
\text { representation as } \\
\text { an active search } \\
\text { process (3) }\end{array}$ & $\begin{array}{c}\text { News practice } \\
\text { knows no } \\
\text { diversity (4) }\end{array}$ & $\begin{array}{l}\text { Reality knows } \\
\text { no diversity (5) }\end{array}$ \\
\hline Involvement & Disengagement & Disengagement & Commitment & Disengagement & Disengagement \\
\hline $\begin{array}{l}\text { Power } \\
\text { position }\end{array}$ & - & - & Change & Conservation & Conservation \\
\hline Objectivism & - & - & Reconstruction & - & Reproduction \\
\hline $\begin{array}{l}\text { Ethical } \\
\text { standards }\end{array}$ & Subjectivism & Absolutism & Absolutism & Situationism & Exceptionalism \\
\hline
\end{tabular}

The first argument (Table 1) is based on the idea that portrayal of diversity would be incompatible with the news making process. The main reasoning here is based on the 'disengagement' ideal. The journalists lack the motivation to seek diversity in their sources because they think it would interfere with the news process. A few quotes:

- $R 8$ (man, age 49, quality newspaper): News is news and the person who is the subject of the news is less important. And 
it's definitely not clever to go and look for that mix, because you risk making news of things that aren't news.

- R16 (man, age 52, popular newspaper): I believe you have to write about somebody if that person is newsworthy. And if that person is a woman or somebody with an ethnic minority background, so be it. But it has to be relevant; we shouldn't, I think, put somebody of ethnic descent in the newspaper, or a man or a woman, merely because we feel that they ought to be heard more often. (...) I don't think l'm a social service.

The ethical standard of journalists who believes in the incompatibility of diverse representation with news reporting is closely connected with subjectivism. Journalists do not view portraying diversity as a worthwhile endeavour. Moreover they see equal representation in news content as an unrealistic goal and therefore one they need not take into account.

The second argument (Table 1) also demonstrates conceptual resistance to the principle of diverse representation - a paradoxical one whose rationale is the notion of equality as a reality. Rather than emphasising the differences between individuals, it posits an abstract equality between them. Everyone being 'equal', there is no need to place any emphasis on the differences. This argument leads to a position of 
disengagement. Here the journalists simply do not look at diversity because it does not matter in their eyes:

- R5 (man, age 46, quality newspaper): I always think it does not matter at all whether it is a woman or a man saying something.

- $R 9$ (woman, age 63, popular newspaper): I refuse to put people into compartments.

This 'equality as reality' point of view exemplifies the 'absolutism' ethical standard. Such a disregard for diversity does not stem from a concern to treat all individuals equally, irrespective of their background (Herrscher, 2002). Quite the opposite: it is precisely because all individuals are unquestioningly deemed equal that it is thought immaterial whether a news report focuses on a man or a woman, or a member of an ethnic majority or minority.

The third argument (Table 1) views diversity as conceptually relevant, affirming the need for journalists to actively represent it. Here it is clear that diverse representation does not just happen. Journalists need to go out there and search for it actively. The quotes below exemplify the position taken by journalists who view portraying diversity as one of their journalistic duties, which reflects the committed ideal type: 
- R1 (woman, age 47, quality newspaper): It's necessary for journalists to take a conscious attitude towards diversity for if you don't, your reader will have the impression that we in Flanders still live in a white middle-class society. Which is not the reality of course.

- R3 (woman, age 29, quality newspaper): I notice that if you want diversity you really need to be actively engaged. (...) Diversity does not come naturally, you need to make an effort.

- R12 (man, age 24, quality newspaper): I think giving attention to diversity is important. (...) It is my social conviction.

By emphasizing the fact that Flanders is no longer a white middleclass society, R1 refers to a need to challenge the current preeminence of white middle-class people. The next quote expresses a need to effect change when referring to the 'societal mix':

- R6 (woman, age 33, quality newspaper): What about the diversity of the people you present in the newspaper? That also means: how representative is your newspaper? Does the mirror of society, which you hold up to your readers reflect a true social mix? 
Additionally, this implies the need to reflect society but in the sense of 'a true societal mix', which involves a reconstruction of the 'truth' (reality) through taking into account all of the members of society. The next journalist also invoked the ideal of reality reconstruction in the sense of a Socratic truth-finding process, considering that a journalist's mission is to represent all viewpoints:

- R2 (man, age 34, popular newspaper): If any problem crops up, it's your task to clearly present all viewpoints. All those concerned in that specific problem must be given a chance to have their say.

This argument also embodies the absolutist ethical standard. Here equal treatment of all individuals is viewed as a universal rule, with equal portrayal in news content a means to achieving that goal.

While some journalists stated their willingness to adhere to the principle of diverse representation, how do they act on it? As stated above, authors indicate that Flemish newspapers consistently fail to account for gender and ethnic diversity. We attempted to find out which arguments journalists provide in defence of this lack of diversity - which they mostly explain by the nature of the source selection routine (see fourth statement in Table 1-'news practice knows no diversity'). In other words the extent 
to which a set of sources meets the diversity criterion is not viewed as particularly relevant or newsworthy. The 'familiarity' and 'expertise' criteria take pride of place, precluding a search for less mainstream sources. Here familiarity helps the journalists work faster as they know what to expect from a source they have used before. Additionally, such familiar sources are more experienced and knowledgeable about the way the media operate, which produces clearer statements that are more easily applicable in a news story. Here are a few quotes to illustrate this:

- R1 (woman, age 47, quality newspaper): If you have a man and a woman who are both experts and you object to political discrimination, you should contact the woman first. But of course, the reality is that you choose the person you know best and who is likely to give the most interesting comment.

- $R 7$ (woman, age 32, popular newspaper): You've got a list of contacts of your own, known quantities you've used before. (...) You tend to reach out to whoever is most likely to give good quotes and express themselves clearly.

In popular newspapers especially, familiarity with the sources is important because of recognisability aspects which are thought to enhance the interest of the public: 
- R13 (man, age 34, popular newspaper): We are a popular newspaper, so the experts we give a voice to should have a certain level of celebrity status.

Another selection criterion that seems to work against source diversification is expertise. Firstly, journalists indicated that there are too few experts with an ethnic minority background available, and too few female experts, especially in such fields as economics. Another reason is, again, familiarity with expert sources. One journalist (R7, woman, age 32, popular newspaper) pointed out that there should be a good reason to use another source rather than the usual expert. This evidences definite conservatism among journalists, at least as far as their sources are concerned. Another recurring explanation is that women tend to respond with greater caution than men when asked to share their expertise with the media, which complicates matters.

Diversity is thus a marginal criterion for most journalists. Their reliance on familiarity and established expert sources can be connected with the 'disengagement' and 'conservation' ideal types. They see no need to portray diversity and neither do they think they owe it to society to diversify their sources, being quite content with their old contacts lists which they always return to. Such a conservative attitude perpetuates the gender and ethnic 
imbalance of news sources. But any journalist intent on giving women and ethnic minorities more visibility should be willing to actively look for other voices. This point of view reflects the 'situationist' ideal: although journalists seem to believe women and ethnic minorities should be better represented in the news, they do not think of such a notion as an ethical standard. As a result they easily disregard diversity in a concrete news situation.

The fifth argument is expressed as 'reality knows no diversity' (Table 1). Here the main explanation for the lack of diversity in the news is the corresponding lack of diversity in societal reality. Society as such is of course diverse, but in certain sectors such as politics, women and ethnic minorities do play a less important role. This is consistent with the abovementioned statement that there are less female experts and experts with ethnic minority background available. Some quotes as illustration for this reasoning:

- R6 (woman, age 33, quality newspaper): Reality has not yet reached that point for we still find many sectors where men are overrepresented, so that the presence of women is significantly smaller.

- $R 8$ (man, age 49, quality newspaper): The number of men and women in political life, for example, is not equal. (...) So 
if you're in political reporting, it's natural to have more men in your articles.

Here journalists assume no social responsibility: they gladly think they are putting a mirror to society. The statement 'it is natural' evidences this disengagement mindset, which leads to a conservative attitude. This is clearly expressed in stating that the problem "will abate over time" (R5, man, age 46, quality newspaper) or "will be naturally resolved" (R8, man, age 49, quality newspaper). Journalists do not feel a need to challenge the current power relationships because they believe they are transitory. Here we have an example of the 'exceptionalism' ethical standard. The lack of diversity in reporting is a problem that hopefully will go away but that they do not attempt to solve through diverse representation because they think their mission is solely to reflect reality ('reproduction').

To sum up, the answer to the first research question is that the arguments in favour of a diverse source selection belong to the 'active ideal' end of the journalistic cultural spectrum. Overall, the ideal type which places the most emphasis on diverse representation implies a societal commitment. However, a majority of our respondents feel they have no responsibility to society, which indicates that Flemish journalists tend to gravitate towards the Liberal Model when it comes to representing women 
and ethnic minorities (RQ2). They strongly feel that they should not be required to incorporate diversity considerations in their news production process. There is very high resistance to the notion that people should be given a voice in the news for the sake of remedying existing or perceived discrimination - that is, using a female or ethnic minority source primarily because they belong to an underprivileged group. A few illustrative quotes: - R2 (man, age 34, popular newspaper): There's no need to drag in people who are not at all involved, just for the sake of... It'd be absurd to use a female source even though she has hardly anything to do with the story - just out of principle.

- R12 (man, age 24, quality newspaper): I do not believe in political correctness. (...) In the 1990s the media concealed it [the ethnic background of criminals]. (...) Resulting in a decline of trust in journalists. (...) You need to call a spade a spade. (...) I understand the motives, but in the long run... bad idea. - R15 (man, age 46, quality newspaper): Of course you need to be careful that the whole business doesn't become a targeted search for a female voice or a voice from an ethnic minority. You risk giving the floor to second-rate figures, for diversity's sake. That would be wrong. 
This is stated in the same breath as the notion that equality is the rule and that there is no need to artificially bring unnecessary voices into the news reporting:

- R5 (man, age 46, quality newspaper): In my perception women and men are completely equal. (...). I don't see why women and/or ethnic minorities or whoever should get preferential treatment, it annoys me (...) I live by the rule of complete equality.

\section{Conclusion and discussion}

The main explanation for the on-going dominance of white male news sources is laziness and lack of awareness of the diversity issue on the part of journalists. Some respondents did note rate diverse representation at all - not even conceptually - as a newsworthy selection criterion, while others pointed to practical difficulties in bringing it into journalistic practice. Only a few tended to actively look for diversity on a daily basis. There is no doubt that journalists willing to portray diversity will need to adopt an active stance based on social responsibility. Conversely, those who feel no pressing need in this matter will stick to their passive journalistic practices. 
Of course, the ideal of representing all perspectives equally is unattainable in practice (Gans, 2011), but if fighting the social exclusion of women and ethnic minorities matters to them, journalists should be willing to put some effort into finding female and/or 'non-white' voices.

Unfortunately, in their daily work journalists tend to follow inflexible routines, with the alleged incompatibility between diverse representation and news practice a self-fulfilling prophecy. In selecting their sources the Flemish journalists follow the same procedures as their American colleagues (Robinson and Culver, in press): they rely on their own network and sources. What remains unclear, however, is the reason why these sources are predominantly male and ethnically mainstream. Journalists should be willing to refresh their contacts lists to enable change to take place. By referring to the same sources over and over they impede progress in the representation of women and ethnic minorities. As an example, one respondent candidly stated that he often used the same sources partly out of laziness.

The 'lack of diversity' in society can be seen as a convenient fiction the respondents used to justify their networks' highly mainstream makeup. What we have here is something of a vicious cycle: absent diverse sources there can be no diverse representation. But should they work on increasing 
the visibility of women and ethnic minorities in the news, journalists would help them gain social status and power (e.g. Avraham and First, 2010), which in turn would bring forth more non-mainstream sources. It must be said that the increasing social, economic, and political visibility of women worldwide has not led to more visibility in the news (Ross et al., in press). This vicious cycle can be broken only by a changeover from passive journalistic practices to more active ones, with journalists really looking for the 'other' voice. A possible option to raise awareness of diversity among journalists is to discuss the issue more clearly among the editorial staff. In this respect, an ombudsperson could do useful work by acting as impartial intermediary, able to weigh more on the behaviour of individual journalists than any editorial intervention (Herrscher, 2002).

This study identified five categories of journalists based on as many arguments or viewpoints expressed by the respondents regarding diversity in news reporting (Table 1). We should state here that this is an ideal typology, and that journalists may well shift from one such viewpoint to another as they go from one news story to the next over the course of their day.

A final comment pertains to the scope of the study. As stated above, in Flanders the dominant model is the Democratic Corporatist Model, which 
would purport to indicate that the findings should be useful with respect to any country belonging to this model. But the question remains whether such a model still exists. Western journalists seem to be moving towards a more global, Liberal Model, their common ground being the passive, oldfashioned interpretation of objectivity (Wiik, 2014). Concerning the representation of women and ethnic minorities this shift is also noticeable. Although responsibility to society is a major characteristic of the Democratic Corporatist Model, our respondents showed no great inclination to view diversity as newsworthy. It may be that the specificity of diverse representation deters journalists from taking up social responsibility. For instance a recent study pointed to a shift away from political correctness on the subject of ethnic minorities among Dutch journalists (Müller and Frissen, 2014), and such seems to be the case among their Flemish colleagues as well. More case studies about concrete interpretations of objectivity related to passive versus active approaches are needed to clarify this subject. Furthermore, to deepen the insights about the diverse representation issue, there is a need to draw cross-country comparisons of the views of journalists in countries that favour the Democratic Corporatist Model as well as those that use the Liberal Model. 


\section{NOTES}

(1) The present study was carried out solely in Dutch-speaking Belgium (Flanders), whose journalism culture is based on the North/Central European or Democratic Corporatist Model while French-speaking Belgium tends to favour the Mediterranean or Polarized Pluralist Model (according to Hallin and Mancini's typology, 2004).

\section{REFERENCES}

Avraham E and First A (2010) Can a regulator change representation of minority groups and fair reflection of cultural diversity in national media programs? Lessons from Israel. Journal of Broadcasting \& Electronic Media 54(1): 136-148.

Bousetta H and Jacobs D (2006) Multiculturalism, citizenship and Islam in problematic encounters in Belgium. In: Modood T, Triandafyllidou A and Zapata-Barrero R (eds) Multiculturalism, Muslims and Citizenship: A European Approach. London: Routledge, pp. 23-36.

Braun V and Clarke V (2006) Using thematic analysis in psychology. Qualitative Research in Psychology 3(2): 77-101.

Broersma M and Peters C (2017) Introduction Towards a Functional Perspective on Journalism's Role and Relevance. In Peters C and 
Broersma M (eds) Rethinking Journalism Again: Societal Role and Public Relevance in a Digital Age. London: Routledge, pp. 1-18.

Deuze M (2005) What is journalism? Professional identity and ideology of journalists reconsidered. Journalism 6(4): 442-464.

Dixon $T L$ and Williams C $L$ (2015) The changing misrepresentation of race and crime on network and cable news. Journal of Communication 65(1): 24-39.

Djerf-Pierre M (2011) The difference engine: Gender equality, journalism and the good society. Feminist Media Studies 11(1): 43-51.

Duncan J and Reid J (2013) Toward a measurement tool for the monitoring of media diversity and pluralism in South Africa: A publiccentred approach. Communicatio 39(4): 483-500.

Gans H J (2011) Multiperspectival news revisited: Journalism and representative democracy. Journalism, 12(1): 3-13.

Gemi E, Ulasiuk I and Triandafyllidou A (2013) Migrants and media news making practices. Journalism Practice7(3): 266-281.

Hallin D and Mancini P (2004) Comparing media systems: Three models of media and politics. Cambridge: Cambridge University Press.

Hanitzsch T (2007) Deconstructing Journalism Culture: Toward a Universal Theory. Communication Theory, 17(4): 367-385. 
Hanitzsch T, Hanusch F, Mellado C, Anikina M, Berganza R, Cangoz I, Coman M, Hamada B, Hernádez ME, Karadjov CD, Moreira SV, Mwesige PG, Plaisance PL, Reich Z, Seethaler J, Skewes EA, Noor DV and Yuen EKW. (2011) Mapping journalism cultures across nations. A comparative study of 18 countries. Journalism Studies 12(3): 273293.

Herrscher R (2002) A Universal Code of Journalism Ethics: Problems, Limitations, and Proposals. Journal of Mass Media Ethics 17(4): 277289.

Horsti K and Hultén G and Titley G (2014). Introduction. In Horsti, K, Hultén G and Titley G (eds) National Conversations: Public Service Media and Cultural Diversity in Europe. Bristol: Intellect Books, pp. 118.

Jakubowicz A (2014). Afterword: And that's goodnight from us: cultural diversity and its challenge for public service media In Horsti, K, Hultén G and Titley G (eds) National Conversations: Public Service Media and Cultural Diversity in Europe. Bristol: Intellect Books, pp. 225-239. Malik S (2014). Diversity, broadcasting and the politics of representation. In Horsti, K, Hultén G and Titley G (eds) National Conversations: 
Public Service Media and Cultural Diversity in Europe. Bristol: Intellect Books, pp. 20-41.

McQuail D (1992) Media Performance: mass communication and the public interest. London: Sage.

McQuail D (2010). McQuail's mass communication theory. London: Sage. Müller F and Frissen R (2014) De diversiteitsparadox: Over de veranderende relatie tussen journalistiek en etnisch-culturele diversiteit. Tijdschrift voor Communicatiewetenschap 42(3): 265-285.

Napoli P (1999) Deconstructing the diversity principle. Journal of Communication 49(4): 7-34.

O'Loughlin B (2006). The operationalization of the concept "cultural diversity" in British television policy and governance. Working Paper 27, Center for Research on Socio-Cultural Change, Oxford.

Raeijmaekers D and Maeseele P (2015). Media, pluralism and democracy: what's in a name?. Media, Culture \& Society 37(7): 10421059.

Raeymaeckers K, Heinderyckx F, De Vuyst S, Libert M, De Maeyer J, De Dobbelaer R, Le Cam F, Deprez A and De Keyzer J (2013) De Belgische journalist in 2013: een zelfportret. Gent: Academia Press. 
Reich Z (2009) Sourcing the news. Key issues in journalism - An innovative study of the Israeli press. Cresskill, N.J. : Hampton press. Robinson S and Culver K B (in press). When White reporters cover race: News media, objectivity and community (dis) trust. Journalism.

Ross K and Carter C (2011) Women and news: A long and winding road. Media, Culture \& Society 33(8): 1148-1165.

Ross K, Boyle K, Carter C and Ging D (in press). Women, Men and News: It's life, Jim, but not as we know it. Journalism Studies, 1-22.

Silverstone R (2008) Media and Morality: On the Rise of the Mediapolis. Cambridge: Polity.

Skovsgaard M, Albæk E, Bro P and de Vreese C (2013) A reality check: How journalists' role perceptions impact their implementation of the objectivity norm. Journalism 14(1): 22-42.

Soderlund G (2013) Approaches to Gender and Sexuality in Media History. In: Valdivdia A (ed) The International Encyclopedia of Media Studies. Blackwell Publishing, pp. 1-17.

Ter Wal J, d'Haenens L and Koeman J (2005) (Re)presentation of ethnicity in EU and Dutch domestic news: a quantitative analysis. Media, Culture \& Society 27(6): 937-950. 
Valentine S and Fleischman G (2002) Ethics Codes and Professionals' Tolerance of Societal Diversity Journal of Business Ethics 40(4): 301312.

Van Cuilenburg J (2016). Waarheidsbevinding als journalistieke missie. Een opmaat naar een kennisleer. Amsterdam: Boom Lemma.

[authors]

Van den Bulck H and Broos D (2011) Can a charter of diversity make the difference in ethnic minority reporting? A comparative content and production analysis of two Flemish television newscasts.

Communications 36(2): 195-216.

Voakes P, Kapfer J, Kurpius D and Chern, D (1996) Diversity in the News: A Conceptual and Methodological Framework. Journalism \& Mass Communication Quarterly 73(3): 582-593.

WACC (2015). Who Makes the News? London: World Association for Christian Communication.

Ward S J (2010) Inventing objectivity: New philosophical foundations. In: Meyers C (ed.) Journalism Ethics: A Philosophical Approach. New York: Oxford University, pp. 137-152.

Wiik J (2014) Towards the Liberal Model. The professional identity of Swedish journalists. Journalism Practice 8(5):660-669. 
